\title{
Explorers Virtual Internship: Fostering Rightful Presence and Sense of Belonging in an Online High School Internship Program
}

\author{
Katharine Marshall Lalish ${ }^{1}$, Shelley Stromholt ${ }^{2}$, Natalie Curtis ${ }^{3}$, and Jeanne Ting Chowning ${ }^{1}$ \\ ${ }^{1}$ Science Education and ${ }^{3}$ Government and Community Relations, Fred Hutchinson Cancer Research Center, Seattle, WA and ${ }^{2} A s p e c t$ Research + Evaluation, \\ Seattle, WA
}

Keywords: High school students, virtual internship, rightful presence, belonging, mentors, virtual mentorship, biomedical research

Publication Date: July 19, 2021

DOI: https://doi.org/10.15695/jstem/v4i2.07

\begin{abstract}
This paper describes the "Explorers Virtual Internship" (EVI), which was designed and presented in the 2020-21 school year by the Fred Hutchinson Cancer Research Center. Despite our initial wariness about creating a virtual internship, the shift helped us make valuable innovations to our programming. EVI paired 11 high school interns with mentors to work on individual research projects. We designed our program to foster a sense of belonging and "rightful presence" in biomedical research among the interns, all of whom came from backgrounds underrepresented in science. In addition to the research experience, we also focused on ethical issues, career awareness, community building, identity/belonging, and leadership/agency. Interns reported increases in their perceptions of the overlap of their identity and those of STEM professionals. They also reported increases in their knowledge of STEM concepts and capacity to demonstrate STEM skills (n=10). Open-ended survey responses indicated that students' uptake of scientific practices and sense of belonging were interrelated with their relationship with their mentors, and that students felt a sense of community with other students despite being in a virtual environment. We also provided programming for mentors, who indicated that learning and thinking about rightful presence and belonging was helpful for their role.
\end{abstract}

\section{INTRODUCTION}

In this paper we describe the Explorers Virtual Internship (EVI), a new academic year virtual internship program for 10th-12th graders in which interns are paired with scientist mentors at Fred Hutchinson Cancer Research Center ("Fred Hutch"). Our overall aims are to provide the interns with a meaningful research experience under the mentorship of a scientist, interest them in STEM careers, and give them a sense of belonging in the field of biomedicine.

In 2020, the COVID-19 pandemic challenged us to rethink our Explorers high school student programming at Fred Hutch. We had previously run the Explorers program as a 2-week in-person summer outreach program aimed at rising 10th-11th graders from underrepresented backgrounds in STEM. We were not able to run the in-person program in the summer of 2020 and instead had a scaled-down virtual program (Virtual Explorations in Cancer Research, VECR) that met for 3 hours per week for 6 weeks. In conversations with our VECR students and Explorers alumni, we learned that COVID-19 restrictions were causing major disruptions to the lives of high schoolers, especially those from marginalized communities. Our students were more eager than ever to stay connected with us and make new connections with scientists and like-minded students. They wanted to be productive and find purpose by being involved in research. We realized that making personal connections and research experiences were more valuable than ever and that instead of reducing programming in response to the pandemic, we needed to create more opportunities for student engagement. To this end, we created the new, paid, remote high school program for the 2020-2021 academic school year - the Explorers Virtual Internship (EVI). This paper describes our experiences in developing this internship.

\section{BACKGROUND}

Fred Hutchinson Cancer Research Center is a nonprofit research organization located in Seattle, Washington, that focuses on preventing and finding cures for cancer and related 
Table 1. Comparison of Explorers Programs.

\begin{tabular}{|c|c|c|c|}
\hline Program & Traditional Explorers & Virtual Explorations in Cancer Research (VECR) & Explorers Virtual Internship (EVI) \\
\hline $\begin{array}{l}\text { Meeting } \\
\text { location }\end{array}$ & Fred Hutch campus & Zoom video conferencing & Zoom video conferencing \\
\hline Year(s) & 2018-2019 & 2020 & $2020-2021$ \\
\hline Month(s) & August & July-August & November-June \\
\hline \# of weeks & 2 & 6 & 32 \\
\hline Schedule & Full day, M-F & $3+$ hours/week & $5+$ hour/week \\
\hline Students & 2 cohorts of 16 (32 total) & 1 cohort of 30 & 1 cohort of 11 \\
\hline Mentors & 2 Explorers alumni & 1 Explorers alum, 4 college-age interns & 6 career scientists \\
\hline Activities & $\begin{array}{l}\text { Hands-on labs and activities, guest } \\
\text { speakers, lectures, discussions, writing }\end{array}$ & $\begin{array}{l}\text { Virtual activities, guest speakers, lectures, } \\
\text { discussions, writing }\end{array}$ & $\begin{array}{l}1 \text { on } 1 \text { mentorship, research project, } \\
\text { virtual activities, guest speakers, } \\
\text { lectures, discussions, writing }\end{array}$ \\
\hline Goals & $\begin{array}{l}\text { Intro to Fred Hutch research and } \\
\text { education programs, science careers, } \\
\text { create personal connections }\end{array}$ & $\begin{array}{l}\text { Intro to Fred Hutch research and education } \\
\text { programs, science careers, create personal } \\
\text { connections }\end{array}$ & $\begin{array}{l}\text { Experience and build confidence } \\
\text { around the } 6 \text { pillars (Figure 1) }\end{array}$ \\
\hline
\end{tabular}

diseases. Research at Fred Hutch ranges from using model organisms to learn about basic biology to conducting human clinical trials to using computational biology to learn about the spread of infectious diseases such as COVID-19. EVI is part of a larger suite of integrated programs that form a continuum of opportunities at Fred Hutch for students from 10th grade through graduate school.

The Explorers program is aimed at providing an introductory experience to our youngest students: rising 10th and 11th graders. The Explorers program was envisioned as the outreach component of the larger National Cancer Institute Pathways to Cancer Research grant (R25 CA221770 Chowning/Torok-Storb), a comprehensive and integrated suite of initiatives that also includes a teacher research component, a curriculum development component, and a 9-week summer undergraduate research internship. While Explorers was designed as a two-week, in-person summer program, we modified it in 2020 and 2021 to be completely virtual. In response to COVID-19, we also designed the new EVI program described here, inviting students who had participated in one of our short introductory summer outreach programs in the past to our new school-year virtual program. Table 1 provides of summary of the various recent iterations to our programming.

EVI was designed based on student input and feedback, as well as theoretical constructs of rightful presence (Calabrese Barton and Tan, 2019) and Carlone and Johnson's (2007) dimensions of science identity. We focused on Calabrese Barton and Tan's (2019) application of critical justice studies on guest/host relations in sanctuary cities to move the program beyond limited discourses of inclusion to teaching and learning that recognizes and embraces political struggle. The authors point out that inclusion efforts typically do little to disrupt systemic inequities and too often are limited to inviting marginalized people in as guests without confronting historical and present injustices that are central in the work. In this program, we applied the rightful presence framework in our efforts to organize activity in a traditionally white-dominated research space in ways that redistributed power and agency to BIPOC interns. We prioritized supporting them as integral and valuable collaborators, capable of creating new social futures. In cohort meetings and mentor workshops, we drew on Carlone and Johnson's (2007) model of science identity, to focus on program features that supported interns to demonstrate competence, make authentic contributions, and provided explicit opportunities for recognition (both self-recognition and recognition by others who matter to them). We aimed to create an environment in which interns felt supported to bring their whole selves and cultures to their work.

\section{PARTICIPANTS}

We selected 10 prior Explorers/VECR alums and invited them to participate in EVI. Our selection was based on our prior experiences with these students as enthusiastic, motivated, curious, interested in science, and ready for a new challenge. In many cases, students had approached us looking for additional opportunities after their summer program with us. An additional student joined our group at the request of a mentor scientist, bringing our total to 11 . This mentor had already committed to working with a particular young Black student, but she was hoping to provide more community for him. The final group consisted of 8 females and 3 males. Nine of the students identify as Black or African, 1 as Latinx, and one as multiracial Latinx/White (for additional demographic information, see Appendix A).

\section{PROGRAM DESIGN}

Six major conceptual areas ("pillars") were foundational to the design and organization of EVI and aligned with our overall goals for the program: research experience, ethical issues, college and career awareness, community 


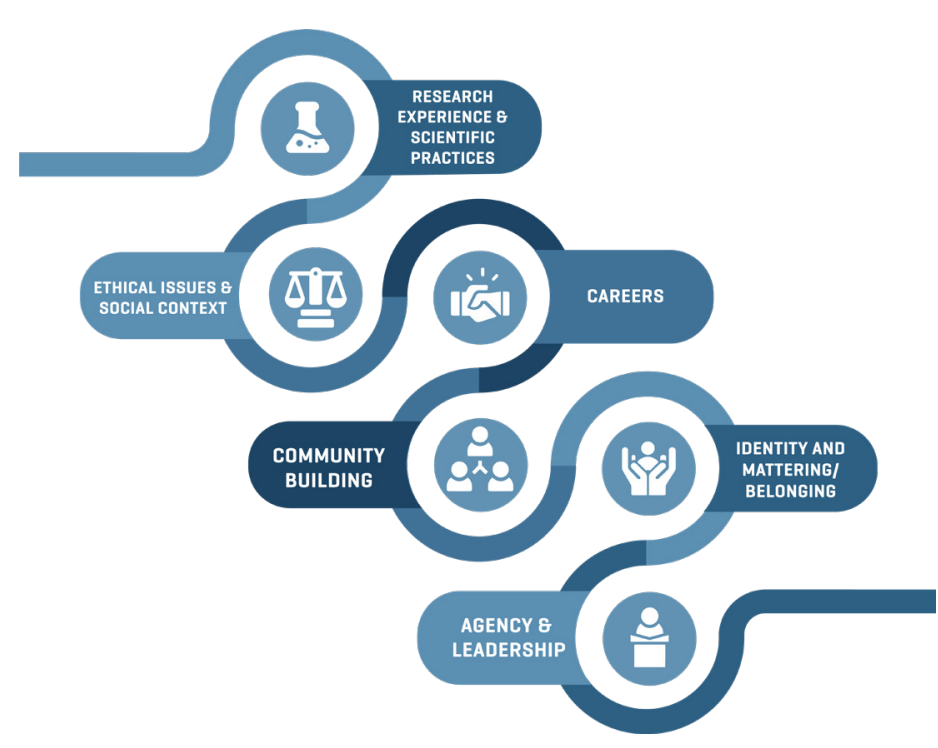

Figure 1. Program Design Overview.

building, identity/belonging, and leadership/agency. These areas, which are summarized in Figure 1, Program Design Overview, are discussed in more detail below. For a detailed schedule of weekly activities mapped to these pillars, see Appendix B.

Research Experience and Scientific Practices. Our goal for the research experience was to have interns engage with a scientific mentor in developing a project, and to learn more about scientific practices and processes. We grouped interns into pairs and assigned them volunteer scientist mentors based on mutual interest and experiences. Mentors represented a wide range of scientific expertise and included post-doctoral scholars, lab technicians, staff scientists, and faculty. One mentor identified as male, and the remainder identified as female. While we did not ask demographic information from mentors, the majority were white.

The main role of the mentors was to support interns in the research experience pillar. Each mentor worked with two interns (except for the student and mentor who had already wanted to work together) so that the interns could discuss their projects or work together. We left the scope and subject up to the mentors but encouraged them to consider the background and interests of their interns as much as possible. For example, interns who did not have a clear idea of what they wanted to research tended to work on projects closely related to their mentor's work. Some interns showed a strong interest in a certain population or disease, so their mentor helped them define a project around that interest. Others had the goal of improving their coding skills and were matched with a mentor with coding expertise. We asked our mentors to focus on ensuring a positive experience for the interns over having a complete and publishable product at the end.

Students aimed to spend a minimum of four hours total each week on the research component of their internship (they averaged 3.6 hours/week). Our mentors helped their interns define projects, learn the background to be able to investigate that topic, learn the skills necessary to carry out the project, and figure out how to present their project. The mentors met with their interns for at least 30 minutes per week via Zoom. During this time, they checked on their interns' progress and scientific understanding and helped their interns plan next steps. In addition to the 30-minute meetings, we asked interns to spend an additional 3.5 hours/ week working on their project independently. However, we wanted to give the interns flexibility to work less when busy or more when they had time and interest. Topics for intern projects included: the impact of chemotherapy in early childhood on long term brain development, using gold nanoparticles to target cells for gene editing, epitopes in COVID-19, early breast cancer treatment in populations experiencing health care inequities, using machine learning to study biomedicine, the impact of high and low sugar diets in model organisms (Drosophila melanogaster), understanding how proteins are involved in cell quiescence, and the impact of oxytocin and epigenetics on maternal mortality.

The interns also met virtually as a group with Fred Hutch Science Education staff weekly for 1-1.5 hours. During these times, we focused on the remaining five pillars of our program design: ethical issues, college and career awareness, community building, identity/belonging, and leadership/ agency. These overlapped to some extent - for example, mentors in the research experience often talked about their own college and career pathways with students.

Ethical Issues and Social Context. Our goal with this pillar was to help students consider and analyze ethical issues in biomedical research. We also wanted students to understand and appreciate the ways that science, being a human endeavor, is inextricably intertwined with a larger social context. Throughout the program we maintained flexibility in our agenda, allowing space for discussing challenging and historical events during this unique academic year. This was particularly true for ethical issues. Interns received instruction in bioethical principles and foundational ideas, considered ethical dimensions of current issues, and discussed the bioethics of significant historical cases.

At the end of 2020, COVID-19 vaccines were being developed and regulators were outlining how the vaccine should be equitably distributed. This was such a poignant and relevant current event that we felt it needed to be addressed. Interns read and discussed one of three proposals for how vaccines should be equitably distributed (from WHO-SAGE, CDC-ACIP, and National Academy of Medicine-NASEM) and then presented their distribution guidelines to the group. The students discussed what they agreed with, what was not clearly laid out, and what they disagreed with in each set of guidelines. They formed their own opinions about how the 
US should prioritize groups and they were primed to follow the news as vaccines started rolling out to different groups at the beginning of 2021. It was an excellent opportunity for them to judge the policies from their own ethical perspective, and then follow what happened in real life.

Interns also had a more formalized bioethics series over the course of four meetings in which they learned about biomedical ethical principles (respect for persons, beneficence, non-maleficence, and justice) as well as critical ethical approaches that focus attention on underlying power structures and the importance of maintaining care and relationships. We used resources from the NIH Exploring Bioethics curriculum supplement [Education Development Center, 2009] and bioethics lessons from the Northwest Association for Biomedical Research and from Fred Hutch developed with Science Education Partnership Award (SEPA) NIH funding [Teacher Center, NWABR; SEP Curriculum, Fred Hutchinson Cancer Research Center]. We considered real-life ethical decisions made by doctors, explored inequities in healthcare, and discussed ethics in research, particularly the need for community-based participatory research (CBPR) approaches when partnering with research participants. We introduced, as an example, Fred Hutch's CBPR efforts with the migrant farmworker community in Eastern Washington to research pesticide/herbicide exposure collaboratively with community members and leaders. We also discussed ethical issues that might arise in their internship research lab settings.

In the spring, the interns led their own meetings about bioethics with a focus on social justice and science. We leveraged curricula that Science Education at Fred Hutch had previously developed and had small groups of interns review the materials and then lead a discussion or activity on the topic. Our topics included, "Is race biological?", "How can wrongfully convicted people be exonerated using science?" and "How has COVID-19 highlighted and increased inequities in health care?" These meetings allowed interns to transition from participating in discussions to leading their own sessions on complex issues.

Careers and Career Awareness. We explored careers with interns and discussed the next steps in their own journeys. Interns discussed their practical concerns about college with counselors (volunteers from a local independent school). Our guest college counselors presented twice and focused on interns' immediate goal: getting into college. In the first session, they led a discussion about how students could determine which schools to apply to, what to include in applications, financial aid and scholarships, and common misconceptions about the application process. One of our interns was deferred for early decision at her top choice college and felt upset about the result. One of our college counselors advised her on how to compose a follow-up email to the college, and the intern ended up being accepted in the regular decision round.

In the second session with the college counselors, the interns became an admissions team and were tasked with evaluating three mock-applicants for their mock-college: rejecting one, waitlisting one, and accepting one. The activity gave interns insight into what admissions officers see when they receive applications. The interns struggled to pick just one student to accept. Our goal was to highlight that college rejection is not a reflection of how smart you are, your ability as a student, or your personal worth. During reflection, interns said that they thought it was interesting to learn that different colleges are looking for different types of applicants and that devotion to activities can sometimes count for more than grades and test scores.

The interns also heard from two career panels, one with community health educators from Fred Hutch's Office of Community Outreach and Engagement, and the other with undergraduate Science Education interns. These panels gave our interns access to more connections and allowed them to hear from people with different backgrounds and in different phases of their lives. For example, each community health educator works with a different general community group (rural, urban and Hispanic/Latinx, Black, and Indigenous). Several of our students identify with these communities and are also interested in public health careers.

We also had inspiring guest speakers, including a surgeon and an anesthesiologist, who both identify as Black women. They shared the paths their careers took, the challenges they overcame, and answered students' questions about medicine. Students also had the opportunity to attend our bi-weekly Hutch@Home virtual speaker series and virtual field trips and to learn about a wide range of careers at Fred Hutch and in STEM.

In order for students to broaden their networks and learn about other careers, we also asked them to arrange two informational interviews. These interviews could be with people who work outside of Fred Hutch or with researchers who focus on topics other than biomedicine. For the most part, mentors helped interns set up the informational interviews, but the Science Education staff also helped, or the interns could set up on their own interviews if desired. For example, one intern whose family was originally from Uganda and is interested in medicine interviewed our Managing Director of Global Oncology, who helps oversee Fred Hutch's collaboration with the Uganda Cancer Institute.

Community Building. Given that community building has been hard during this time of virtual learning, we spent extra time focusing on creating a sense of community among the interns and with others in the Fred Hutch community. While some students had met each other prior to EVI, others had not. In three of our early meetings, icebreaker activities provided opportunities for interns to get to know one another. 
We continued to build on this by having the interns share their personal journeys and by sharing the successes and challenges in working with their mentor. These strategies are detailed more fully in the identity and belonging and research experience sections. We also matched each mentor to two interns so that they could get to know each other. Interns worked with each other on several group projects, which helped build community. Although the online environment presented challenges, there were also some affordances - for example, the interns enjoyed joking with each other in the chat window and bonding over things like food preferences.

Identity and Mattering/Belonging. Our strong focus on the pillar of identity and belonging was a defining feature of EVI. We emphasized this goal in our first few meetings and kept it central to every meeting for the rest of the program. In our first meeting, the interns briefly introduced themselves and were then sent to a breakout room with one other person where they asked and answered more in-depth questions about each other. When we came back to the full group, each intern introduced their breakout room partner. We then had the interns define and agree upon a set of norms. Our last activity of the first meeting was to have the interns share what topics they wanted to cover during the year on a Padlet digital bulletin board and to "like" the ideas of others. We felt it was important to spend time focusing on who the interns are, making connections with other interns, and sharing what they wanted to get out of this experience.

Absolutely key to our program's success was our EVI Student Advisor, Natalie Curtis, who works at Fred Hutch as a Program Manager in our Government and Community Relations department. Ms. Curtis's background includes community organizing and advocating for health equity. She not only made connections with students and contributions to our program design, but she also provided us with invaluable contacts to BIPOC researchers, medical professionals, and community members who were guest speakers. Furthermore, she provided positive representation as a successful and passionate Black woman.

In the third meeting, Ms. Curtis presented her "Personal Journey", sharing her experience growing up in Texas and how she eventually found her profession at Fred Hutch. Her personal journey served as a blueprint for each intern to share about their own personal journey with the group. The interns were given simple directions: "Please sign up to share about your personal journey. Questions you may choose to consider: What have been formative experiences for you? How did you end up where/how you are now? What are your career and personal goals and how did you decide on those goals? Share as much or as little as you are comfortable with. Slides with images are encouraged, though not required. Please aim for 12 to 15 minutes." The aim was to give interns agency to decide what they were comfortable sharing and to focus their journey on what felt important to them. For many, this included a slide deck with images and a recounting of their family members, ethnic heritage, family traditions, friends, their school activities, their Meyers-Briggs personality type, and what kind of career they would like to have.

For example, one intern started by sharing about their pride in their family; one parent immigrated to the US and the other parent is a member of city council. The intern then covered their likes (pizza, tennis, Star Wars) and dislikes (Brussel sprouts, horror movies, hockey). From there, the intern shared about their passion for leadership, community outreach, and medicine. This intern's career goal was to go to college and major in biology and then go to medical school (all personal details shared with this intern's consent). By highlighting the things that were deeply important to their identity alongside lighter dimensions (such as their favorite foods/music/shows), interns were able to get to know each other better, while also connecting and having fun with each other. By prior agreement, these were recorded to be available to mentors as well. We also asked our guest speakers to share their personal journeys into their professions. Our goal was to help interns further gain a sense of identity and belonging by meeting role models who shared how they became involved in science. This personal sharing was meant to humanize the professional role models, build trust, and let each guest bring varied dimensions of their identities to the interns.

Agency and Leadership. We wove opportunities to practice leadership and agency throughout EVI, in order to support our interns in taking on influential roles and defining their own futures. Interns helped determine the topics of our meetings and (in many cases) their projects with their mentors. As part of April Minority Health Month, Ms. Curtis organized the interns to write Op-Eds and published them to the Fred Hutch community. This gave over 3,000 people access to students' Op-Eds. The students worked in pairs and investigated health inequities in different groups such as African American Non-Hispanic and Indigenous/Alaska Native. The intern Op-Ed about the African American NonHispanic population focused on a senate bill that would improve maternal health in this population. One reader from the Fred Hutch community responded to the Op-Ed saying:

\section{I wanted to thank the interns for highlighting this important topic in their essay this week and espe- cially for bringing it home to Washington to explain the Senate bill 5068 - I'll definitely be looking into it more and contacting my senators.}

To further support the interns in their writing, a physician who has written and published Op-Eds about health inequities in local publications spoke to the students about how to 
write an effective Op-Ed. He showed them how to go about publishing and provided feedback on several of the intern's Op-Eds. Some interns continued to work on their pieces and eventually submitted them to local publications. The goal with the Op-Eds was to give the interns transformative agency to have a real impact on the community.

Interns also led a viewing of a documentary focused on health inequities for their peers. They were able to invite their classmates from their prospective schools that were not enrolled in the program to engage in dialogue about their thoughts about the documentary. Additionally, they led their own meeting on topics related to science and social justice in small groups, giving them a chance to present material to their peers in their own way.

Interns had control over when and how much they worked, and on how they put together their projects and presented them. They were also invited to engage in optional virtual events held by Science Education, such as our journal club, which runs every other week and is open to interns and alumni of our summer programs. Student participants take turns selecting biomedical or bioethical papers to discuss and leading the discussion. Journal club and the virtual Hutch@ Home speaker and field trip series opportunities mentioned previously gave our interns agency to decide how and when they wanted to engage in additional scientific topics and learning throughout their internship.

\section{FOCUS ON VIRTUAL MENTORS}

Our scientist mentors were an integral part of the interns' experience. We put effort into recruiting supportive mentors who were willing to engage and think about how mentoring could mean more than academic and research support. We believed it would be important to provide background information to mentors about the concept of rightful presence. We aimed to enhance not only interns' identities as scientists, but also their sense of belonging with their mentors and lab groups. We found our mentors through previous collaborations and a call-out on a listserv for Fred Hutch employees interested in Diversity, Equity, Inclusion (DEI) and outreach.

In November, we met with each mentor to tell them more about EVI, find out about their previous mentorship experience, and to discuss ideas that they had for intern projects. We also used this initial meeting to inform mentors of our matches and pairings. During the year, we had a total of five hour-long all-mentor workshops to facilitate a supportive community of mentors. In our first mentor workshop, each mentor shared their previous experience and how they were approaching meetings and projects with their interns. At the second and third workshops, we read and discussed articles about mentoring students from historically marginalized backgrounds and about how to support students in times of unrest and social change, with a focus on the Black Lives Matter protests for justice and the riots in the U.S. Capitol related to the Presidential election.

During the fourth and fifth workshops, we focused on providing background on the concept of rightful presence through readings, a presentation, and discussion. Mentors reflected on privileges they might have experienced and power arrangements that students might experience. They gave several examples of how they gained understanding about students' lives and reflected on their own growth and shortcomings. One mentor told the story of one of her students being very stressed out about college acceptances, but that the mentor told her student she had nothing to worry about. The mentor said she was "blown away" because the intern's GPA was 3.94. The mentor thought to herself that her own GPA had been only 3.3, yet here she was working at Fred Hutch - the intern's dream job. However, the mentor had reflected more deeply on this incident afterwards. She noted that it was easy for her to tell the intern not to worry because of the intern's obvious achievements. But the mentor realized that the intern had probably had a host of experiences (such as racial microaggressions) that the mentor was not familiar with as a white person. The mentor noted that for students from historically underrepresented populations, there is probably a real concern of having to go above and beyond to stand out. As a white person, she did not have to deal with those, so it had been easy to dismiss her student's concerns. In retrospect, the mentor said she felt that telling the intern she had nothing to worry about was not helpful.

The Op-Ed assignment about health inequities came up as an example of how discussion of, and reflection on, social injustices were explicitly a part of the mentors' work with interns. Several interns asked their mentors for feedback on their Op-Eds. This led one mentor to suggest to the others that they (as "voices of authority") should encourage selfcare for interns. This self-care might be important for interns as they learn about and work on social injustices in their own communities. Mentors also discussed supporting students to come into STEM research as their whole authentic selves, rather than pressuring them to assimilate. They commented that when they signed up to work with interns, they had a narrower vision of what that entailed - i.e., that they would be focused on helping students learn science. They appreciated the opportunity to think more deeply about what it means to foster a sense of belonging in science.

\section{PRELIMINARY EVALUATION}

Evaluation Methods. Evaluation strategies were designed in alignment with the six program pillars and guided by the rightful presence theoretical framework (Calabrese Barton and Tan, 2019), as well as frameworks related to STEM identity development (Carlone and Johnson, 2007; McDonald et 
A

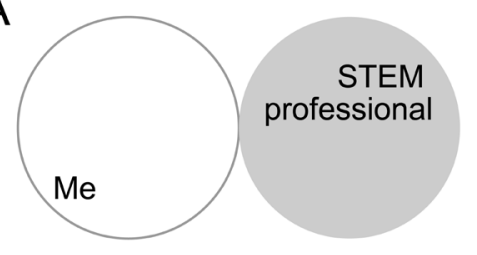

$\mathrm{D}$

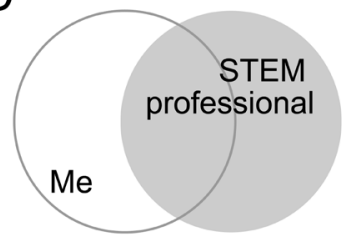

B

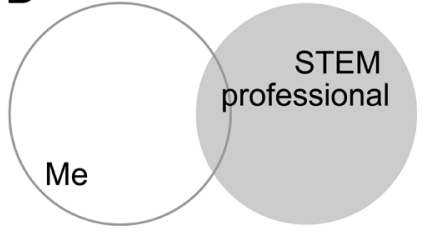

E

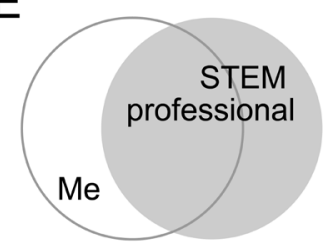

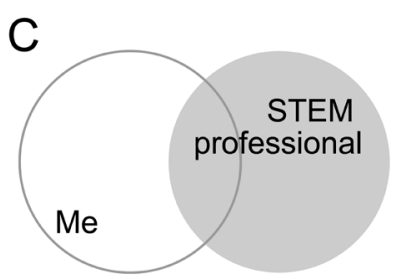

$\mathrm{F}$

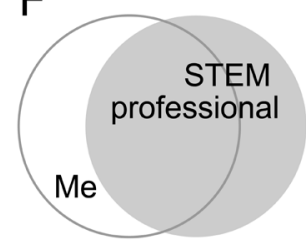

G

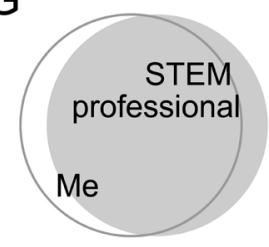

Figure 2. STEM Professional Identity Overlap Measure (From McDonald et al., 2019).

al., 2019). Data were collected and analyzed from three intern check-in surveys and observations of intern and mentor meetings as part of a larger ongoing evaluation study.

Our overall learning question for the evaluation was: What are the affordances and constraints of delivering programming through an online or hybrid environment? We were interested in the following questions: a) What design elements support outcomes such as sense of "rightful presence", belonging, and career identification among underrepresented students? and b) How do these opportunities engage participants in social, cultural, and ethical dimensions of research?

In spring 2021, as part of a regularly occurring checkin survey, interns responded to a set of retrospective pretest measures adapted from the STEM Professional Identity Overlap Measure (McDonald et al., 2019). Interns responded to four survey items designed to measure identification with STEM at three different timepoints: 1) today, 2) before they started this year's internship, and 3) before they initially became involved with Fred Hutch (a year or more prior, for most interns). This allowed us to gauge the influence of our shorter Explorers summer program as well as the longer school year EVI experience.

Interns were instructed to select the picture that best describes the current overlap of the image they have of themselves and their image of what a STEM professional is (see Figure 2). The responses were scored on a scale of 1-7, in which 1 indicated that the interns perceived no overlap between themselves and a STEM professional and 7 indicated the most overlap between themselves and a STEM professional (labeled A-G in Figure 2).

The four items are as follows:

- Indicate the current overlap of the image you have of yourself and your image of what a STEM professional is.
- Indicate the extent to which your knowledge of STEM concepts matches that of a STEM Professional.

- Indicate the extent to which your capacity to demonstrate STEM skills matches that of a STEM professional.

- Indicate the extent to which you think others see your identity as overlapping with a STEM professional.

\section{Preliminary Evaluation Findings.}

Intern STEM Identity. Overall, the ten interns who completed the STEM identity survey items reported important increases in their perceptions of the overlap of their identity and those of STEM professionals over the two time periods measured, both during their previous summer Explorers experience and during this year's remote EVI experience. Interns reported greater perceived overlap with STEM professionals during EVI than after their previous experiences in the summer (Explorers/VECR) or prior to any experience with the Hutch (Figure 3).

The greatest increases were related to interns' perceptions of how they and others see their identity as overlapping with a STEM professional (means of 3.1 before EVI and 4.9 at the time of survey, during EVI). The interns also reported smaller increases this year related to their knowledge of STEM concepts and capacity to demonstrate STEM skills. When asked about interactions with others in the program (e.g., mentor teams, intern cohort) and what typical communication is like, interns described how their relationship with their mentor was intertwined with their learning of professional science practices such as asking questions, reading scientific papers, attending lab meetings, and analyzing data:

For the past couple of weeks [my mentor team and I] have established a routine. This routine starts out with one of us picking a peer-reviewed research paper... Every week we switch roles, for instance this 


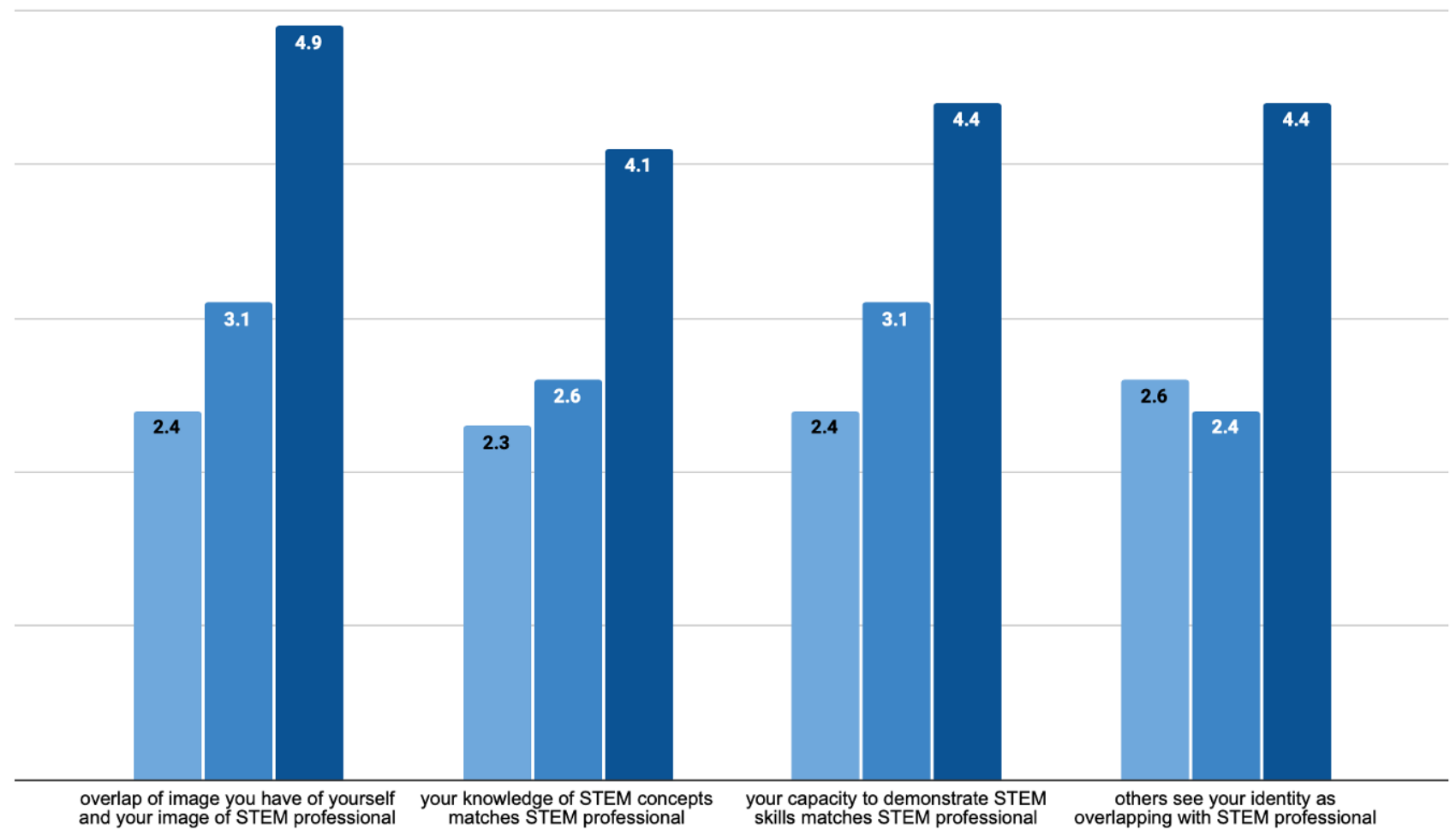

Figure 3. Means of Interns' Responses to STEM Identity Overlap Measure $(n=10)$.

week I picked a research paper that I will be leading the discussion on at our weekly Tuesday meeting with my partner and mentor. We start our meetings by chatting about "what's new?" and lead to a lighthearted conversation that helps to get to know each other. Our mentor often emails us supplements via email like scholarships, podcasts, new info, and lectures. In our meetings we analyze papers and data where we all ask each other questions that help us better understand our topics for the project.

- EVI intern

I try to attend the...lab's meetings on Fridays to learn about some of the research that my mentor's colleagues are doing. And then after that, my mentor and I discuss it, and she summarizes and clarifies any scientific concepts I did not understand.

- EVI intern

Intern Sense of Belonging. Additional findings indicate that interns felt they had strong relationships with their mentors and that working closely with a mentor helped foster a sense of belonging. Several interns specifically used terms such as "comfortable" or referenced their feeling that they belonged to a team when referring to their experiences with their mentors:
I like how comfortable I am around [my mentor] and I can tell she makes the effort to make sure I'm comfortable. Especially since we come from different backgrounds and are covering racial topics and disparities. - EVI intern

I feel very comfortable with my mentor when I am asking about my project and I always make sure to ask questions about something when I need to with her. I work with my mentor individually, so we usually do have social conversations at the beginning of our meeting when it's just the two of us. - EVI intern

[Mentor name] definitely treats me as part of the team, which I really appreciate. She always asks what I think and what I want to do regarding my project. She has also offered to have me meet with some of her colleagues whose work is in pediatric psychology, and their insights will be very helpful to me. Overall, she provides many opportunities for me and I am very happy with my research project's direction thus far! - EVI intern

Furthermore, the weekly all-intern meetings created a sense of community. We asked interns to share with us what was going well and what improvements could be made related to the intern meetings. Interns reported feeling that they were part of a cohesive group despite the virtual nature of 
the program this year. They also noted their interest in the ethical and social dimensions of our discussions about science:

I have enjoyed the activities and discussions we have with each other [in the intern meetings], they are always pretty fun. - EVI intern

I've been enjoying learning about different subjects [in the intern meetings] such as our upcoming bioethics and college applications. I've also been enjoying the breakout rooms and different conversations with the other interns. I've enjoyed the analysis of the pandemic and the vaccine distribution. - EVI intern

Mentor Outcomes. In two EVI mentor workshops, discussions focused on rightful presence and how mentors could create opportunities to disrupt power structures and relationships typical of high school internship programs. We asked mentors to answer questions in breakout sessions after the readings and discussions about rightful presence. When asked how they would describe rightful presence, they responded in ways that suggested an understanding of the concept as well as the need for structural and institutional change: "Being your entire self in any situation", "Restructuring the structures of the science community instead of asking students to restructure themselves to fit". Furthermore, when indicating how they thought rightful presence was different from inclusion, they noted, "Rightful presence involves re-constructing the balance of space that is deserved to everyone to create equal recognition, attention and opportunity. Inclusion is implying using the same social structures or mentality that we need to make space for the 'other'. It is still othering [an] individual."

Mentors were thoughtful about how they were incorporating opportunities for interns to feel welcome and make authentic contributions to the lab and how the workshops had changed their thinking about mentoring. For example, one mentor specifically called out their student's intellectual capability and noted that rightful presence could mean contributing to the science in a meaningful way:

I think toward this idea of making them feel like they belong, I think one thing I've been focusing on is, they're really smart so they can tell if they're doing busy work or if they're doing something that's not contributing so I think findings ways where they can feel like they're making a difference, so they're working on something that's meaningful both to them, but also to the lab. That's something I've had to think really hard about...Last time I had a really fun meeting with one of my interns where we were working through some analysis together and we stumbled on something really interesting and we were both really excited about it and it was really fun. For them to build their skills, that's obviously very important and that's in some ways the main goal, but if they can participate to the point of contributing, just to feel like you've made a difference to the lab, that's what I've been trying to do, to give them meaningful experiences. It takes a lot of work. - EVI mentor

Another mentor noted the unexpected affordances that the virtual setting had provided for students. Although students were at home, they could provide "directions" to those scientists who could be in the lab to execute the student's ideas:

The pandemic actually kinda put us in this new position where, because the students can't be physically in the lab, they have to be able to tell some folks in the lab what to do, so it's been a fun experiment in establishing rightful presence that I don't know that we would have gotten to creatively on our own so that's something we can thank COVID for.

- EVI mentor

When asked how their thinking about mentorship had changed this year, mentors commented on what they had learned from their interns as well as from our discussions about on focusing on more than the science alone during EVI:

My level of awareness has increased a lot with some of the statistics that are involved in racial inequality and health disparities. I had no idea how drastic the difference in maternal mortality is between white and Black women, it's alarming, things like that have really changed my way of being more aware of how many problems there are in all different areas of society...That's something that was part of [the students'] project, they're both working on it but in different biological processes, epigenetics and oxytocin. We read the papers together, having them practice journal club so they'll be prepared for grad school...you see these stats come out in different areas of health care. I've been going on this journey together with them, it's been fulfilling. I've learned more than they have. - EVI mentor

Just realizing that mentorship is so much more than the academic side and it's taking on the student as their whole individual self and helping them become who they want and can be, not just specifically science wise." - EVI mentor 


\section{DISCUSSION}

The first academic year of EVI was still in progress when this paper was written so the evaluation data presented are preliminary. However, the program has exceeded our expectations for a virtual internship. We have been surprised at how enthusiastic both mentors and interns have been and what they have been able to accomplish together. We look forward to their final projects and presentations and plan to use the virtual platform "Gathertown" (https://gather.town) for the program culmination.

Our preliminary survey results indicate that a virtual internship can be effective at helping to build science identity among high school students. Survey questions were designed to examine intern change in several dimensions of science identity, based on Carlone and Johnson's (2007) work. Interns reported growth in all areas, with the largest changes in their own identification as someone who is a scientist (self-recognition). Interns also reported greater overlap with professional scientists in their capacity to demonstrate STEM skills and how others see them. Given that high school students are at the very beginning of their potential STEM career trajectories, it is not surprising that the area where they felt the least overlap with STEM professionals was in their knowledge of STEM concepts. Additionally, their earlier two-week Explorers/VECR outreach summer program had been helpful and had contributed to the growth in their science identity (as noted in the "Before EVI" category of means in Figure 3), but the EVI school-year mentored research experience represented a much larger overall shift in overlap in all identity categories (relative to both the shorter summer experience as well as prior to engaging with Fred Hutch), which was heartening to see in face of the challenges of a virtual program.

The virtual experience has not been without its challenges. Students expressed their frustration at not being able to have an in-person experience (for example, one noted that she loved the research she is doing but that she was sometimes "sad sitting in my room online".) They noted that the online environment was convenient, but they missed being able to learn hands-on skills.

There were many ways in which we were able to successfully adapt components from our traditional face-to-face Explorers to online programming and to also address challenges presented by the current pandemic in new ways. We found the "pillars" we described in this paper helpful in thinking about the program elements that we wanted to highlight in EVI and how they fit together. Although activities related to the pillars were also present in our face-to-face experiences for students, we needed to think about them differently for the virtual experience. For example, EVI research experiences were necessarily more focused on computational and data-related dimensions of research. Similarly, we had done icebreakers and community building exercises in our prior programs, but we spent much more time on these in the virtual world. Providing each intern with 15 minutes to describe their own personal journeys to the rest of the group was particularly helpful. Having a strong community allowed us to have discussions related to ethics and challenging social issues, which would have otherwise been more difficult virtually. The chat feature of Zoom allowed a new type of interaction - a backchannel for banter and discussion - that we did not have in our face-to-face program. A focus on careers was also not new - however, we believe that the virtual environment made it much easier for professionals to allocate time to spend with our group.

We believe that the opportunities for students to exercise agency and participate in leadership opportunities were particularly impactful. The involvement of Ms. Curtis on the team was particularly meaningful and important in promoting intern agency and leadership. Not only could she bring her experience as a community organizer and Black woman to the group, but she was able to arrange opportunities for interns to connect their interests and work with a larger audience. For example, she shared their articles about health inequities through our large internal Community of Employees for Racial Equity network. She also provided leadership opportunities for students to host a screening of a health-related video for their peers.

Perhaps most significant was our aim to incorporate ideas of rightful presence and belonging into our work. Rightful presence is a construct that originates from critical justice studies of refugee communities in host countries and sanctuary cities (Vrasti and Dayal, 2016). It has also been taken up by educators, particularly in informal science education spaces. However, to our knowledge this internship represents a novel effort to try to incorporate ideas of rightful presence into a research experience for youth at a scientific institution. Our team discussed the need for institutions to shift their practices and environments to become places where interns from marginalized communities feel that they belong and to which they can bring their whole selves. Traditionally, science research institutions are organized very hierarchically. To co-create possibilities for elevating youth's lived experience and wisdom, it is necessary to work collectively with the mentors in addition to creating programming for the interns. As one of the mentors noted, "Rightful presence addresses and avoids imposter syndrome". Some of our mentors hold faculty positions, are highly respected within the organization, and can readily influence their peers. We wanted to create opportunities for mentors to reflect on their roles, process and discuss their ideas with other mentors, and act alongside education staff to create an institutional environment that helps students of color feel like science is legitimately a place for them.

We will likely retain many elements of EVI in the future, retaining some of the virtual pieces (for example, some of 
the all-student meetings and presentations), but adding in more lab components when it becomes safe to do so. We feel that there are also many possibilities to develop data- and bioinformatics-related virtual internships in the future that could open connections to our research institute for students in rural and remote areas. Overall, EVI has demonstrated that, despite its challenges, a virtual environment presents many affordances for student science learning. The modifications and approaches that we describe will hopefully provide inspiration and guidelines for others wishing to implement virtual internships.

\section{ASSOCIATED CONTENT}

Supplemental material mentioned herein can be found uploaded to the same webpage as this the manuscript.

\section{AUTHOR INFORMATION Corresponding Author}

Jeanne T. Chowning, PhD, Science Education, Fred Hutchinson Cancer Research Center, 1100 Fairview Ave. N., Mailstop A1-023, Seattle, Washington. chowning@fredhutch.org

\section{Author Contributions}

The manuscript was written through contributions of all authors. All authors have given approval to the final version of the manuscript. We have no known conflict of interest to disclose.

\section{ACKNOWLEDGMENTS}

We would like to thank Carolyn Cohen and Dr. Kristen Bergsman for their thoughtful feedback on the manuscript, as well as the Science Education staff at Fred Hutchinson Cancer Research Center. We especially thank the mentors and student participants for their partnership in this program.

\section{FUNDING SOURCES}

The Explorers program is funded by Pathways to Cancer Research (R25CA221770 PI Chowning/Co-PI TorokStorb), a Youth Enjoy Science Award (YES/CURE), from the National Cancer Institute (NCI) at the National Institutes of Health (NIH). The contents of this article are solely the responsibility of the authors and do not necessarily represent the official views of the NCI or NIH.

\section{ABBREVIATIONS}

CBPR: Community-Based Participatory Research; EVI: Explorers Virtual Internship; "Fred Hutch": Fred Hutchinson Cancer Research Center; NCI: National Cancer Institute; NIH: National Institutes of Health; SEPA: Science Education Partnership Award; VECR: Virtual Explorations in Cancer Research; YES/CURE: Youth Enjoy Science Award

\section{REFERENCES}

Avraamidou, L. (2019). Science identity as a landscape of becoming: Rethinking recognition and emotions through an intersectionality lens. Cultural Studies of Science Education, $1-23$.

Calabrese Barton, A., and Tan, E. (2019). Designing for rightful presence in STEM: The role of making present practices. Journal of the Learning Sciences, 28(4-5), 616-658.

Campbell, T., Lee, H., Longhurst, M., McKenna, T. J., Coster, D., and Lundgren, L. (2021). Next generation science classrooms: The development of a questionnaire for examining student experiences in science classrooms. School Science and Mathematics, 121(2), 96-109.

Education Development Center, National Institutes of Health (U.S.), and National Institutes of Health (U.S.). Clinical Center. Department of Bioethics. (2009). Exploring Bioethics.

Le, P. T., Doughty, L., Thompson, A. N., and Hartley, L. M. (2019). Investigating undergraduate biology students' science identity production. CBE Life Sciences Education, $18(4)$, ar50.

McDonald, M. M., Zeigler-Hill, V., Vrabel, J. K., and Escobar, M. (2019, July). A single-item measure for assessing STEM identity. Frontiers in Education (Vol. 4, p. 78).

Morales-Doyle, D. (2017). Justice-centered science pedagogy: A catalyst for academic achievement and social transformation. Science Education, 101(6), 1034-1060.

Morales-Doyle, D., Varelas, M., Segura, D., and Bernal-Munera, M. (2021). Access, dissent, ethics, and politics: Pre-service teachers negotiating conceptions of the work of teaching science for equity. Cognition and Instruction, 39(1), 35-64.

Pattison, S., Gontan, I., Ramos-Montañez, S., Shagott, T., Francisco, M., and Dierking, L. (2020). The identity-frame model: A framework to describe situated identity negotiation for adolescent youth participating in an informal engineering education program. Journal of the Learning Sciences, $1-48$.

Ribera, A. K., Miller, A. L., and Dumford, A. D. (2017). Sense of peer belonging and institutional acceptance in the first year: The role of high-impact practices. Journal of College Student Development, 58(4), 545-563. 
SEP Curriculum. (n.d.). Fred Hutchinson Cancer Research Center Science Education Partnership. Retrieved April 28, 2021, from https://www.nwabr.org/teacher-center

St-Amand, J., Girard, S., and Smith, J. (2017). Sense of belonging at school: Defining attributes, determinants, and sustaining strategies. IAFOR Journal of Education, 5(2), 105-119.

Teacher Center. (n.d.). NWABR - Northwest Association for Biomedical Research. Retrieved April 28, 2021, from https:// www.nwabr.org/teacher-center

Vrasti, W., and Dayal, S. (2016). Cityzenship: Rightful presence and the urban commons. Citizenship Studies, 20(8), 9941011. https://doi.org/10.1080/13621025.2016.1229196 